\title{
DESENVOLVIMENTO SUSTENTÁVEL E O FÊNOMENO DO EMPREENDEDORISMO COM PNEUS INSERVÍVEIS: UM ESTUDO DE CASO NA “PNEU VERDE”
}

\author{
O. W. C. FAUSTINO* e E. F. LEITE \\ Universidade Federal de Pernambuco (UFPE) \\ otavio.faustino@ufpe.br* \\ Artigo submetido em maio/2013 e aceito em dezembro/2014 \\ DOI: $10.15628 /$ holos.2014.1420
}

\section{RESUMO}

Devido a grande quantidade de pneus que são descartados erroneamente, algumas empresas têm proposto medidas e desenvolvido técnicas com o objetivo de atenuar o impacto ambiental. 0 processamento deste resíduo é um dilema, já que o valor intrínseco dos bens que o constituem são altos, mas o seu aproveitamento cria dificuldades logísticas e tecnológicas que fazem com que os processos de reciclagem tenham custos elevados. Esse trabalho tem como objetivo geral analisar como a reciclagem de pneu pode contribuir para o desenvolvimento local sustentável. A pesquisa em tela, conclui que a ação da Pneu verde traz um alento para a melhoria da qualidade do meio ambiente e da qualidade de vida dos seres vivos.

PALAVRAS-CHAVE: Desenvolvimento Sustentável, Empreendedorismo, Pneu Verde.

\section{SUSTAINABLE DEVELOPMENT AND THE PHENOMENON OF ENTREPRENEURSHIP WITH TIRES: A CASE STUDY IN "GREEN TIRE"}

\begin{abstract}
Due to the large amount of tires that are discarded mistakenly, is that some companies have proposed measures and techniques in order to mitigate the environmental impact. Processing of this waste is a dilemma, since the intrinsic value of the goods that are are high, but their use creates logistical and technological difficulties that make recycling processes have high costs.
\end{abstract}

This work has as main objective to analyze how the tire recycling can contribute to sustainable local development. This research concludes that the action of green tire behind an encouragement to improve the quality of the environment and quality of life of living beings.

KEYWORDS: Sustainable Development; Entrepreneurship, Green Tire. 


\section{INTRODUÇÃO}

Devido à grande quantidade de pneus que são descartados erroneamente, é que algumas empresas têm proposto medidas e desenvolvido técnicas com o objetivo de atenuar o impacto ambiental. Estes pneus não são um resíduo perigoso, mas a sua forma de descarte traz problemas sanitários e dificuldades importantes na sua disposição final. Além de que, se impropriamente armazenados, podem incendiar-se tornando-se um problema de poluição ambiental grave.

O reaproveitamento deste resíduo é difícil, já que o valor intrínseco dos bens que o constituem são altos, mas o seu aproveitamento cria dificuldades logísticas e tecnológicas que fazem com que os processos de reciclagem tenham custos elevados. Os pneus são constituídos essencialmente por borrachas, natural e sintéticas, vulcanizadas e o processo de Pirolise, faz com que o reaproveitamento dos seus constituintes seja possível.

Para o desenvolvimento deste artigo científico, buscou abordar uma questão que está presente na maioria da vida das pessoas e que, no entanto, ocorre um grande problema referente ao impacto ambiental: o descarte de pneus.

Com isto, buscou-se analisar como a empresa Pneu Verde reforma pneus inservíveis, tomando conhecimento de toda cadeia produtiva.

Esse trabalho tem como objetivo geral analisar como a reciclagem de pneu pode contribuir para o desenvolvimento local sustentável. Para complementar o objetivo geral, foram estabelecidos objetivos específicos visando identificar a relação ecológica existente no ciclo de vida do pneu inservível, verificar o impacto ambiental causado com o descarte pneu, construir informações para que a população conheça como pode contribuir para a sustentabilidade ambiental através da reciclagem do pneu.

A pesquisa em tela justifica-se, pois não havendo interesse comercial na reciclagem de pneus usados, estes passaram a serem amontoados em enormes depósitos. Alguns depósitos atingiram milhões de pneus em pilhas, ao ar livre. Estes depósitos introduzem graves problemas de saúde pública.

Primeiro porque, quando expostos ao ar livre, armazenam pequenas poças de água das chuvas no seu interior. Essas pequenas poças de água são ótimas para a procriação e multiplicação de mosquitos.

Segundo porque, em caso de incêndio das pilhas, os fogos criados são muito difíceis de extinguir e têm graves consequências ambientais.

O estudo de caso foi na empresa Pneu Verde Recicladora e Comércio de Resíduos Ltda, com sede à Rua Lourenço de Sá, 165, no bairro de São José, no município do Recife, em Pernambuco. Foi constituída em 05 de maio de 2011 porém, já havia uma OCIPE - DSHT, realizando pesquisa desde 2008, sobre a viabilidade de retirar o resíduo pneu inservível do meio ambiente. 


\section{REFERENCIAL TEÓRICO}

\subsection{O FENÔMENO DO EMPREENDEDORISMO}

O nível de desenvolvimento econômico de um país ou região pode ser mensurado em função de suas atividades na área de inovação e criação de empresas de base tecnológicas, criadas em incubadoras, onde seu maior capital inicial é o intelectual, atuam como uma verdadeira alavanca que impulsionam a transformação de conhecimento em riquezas e acumulação de capital físico e intelectual.

Segundo Drucker,P (1986) A inovação é um termo econômico e social. Seu critério não se baseia na ciência ou na tecnologia, mas nas mudanças no ambiente econômico social e no comportamento das pessoas como consumidores e produtores.

Talvez a explicação da grandeza da obra do empreendedor seja que ele jamais irá encontrar nada, nem finalizar sua tarefa. Baseado na destruição construtiva de Schumpeter. Alguns homens se vangloriam de ter alcançado seus objetivos, mas se enganam pois o verdadeiro empreendedor se compara a uma flecha disparada em qualquer direção e só se salvam os que nunca, jamais atinge o alvo.

Vale salientar que apesar da capacidade criativa de vários teóricos que escreveram sobre empreendedorismo, suas frases, conceitos, teorias, tão como automóveis são, no final das contas construídos com o mesmo chassis - Drucker na gestão, McClelland na psicologia (comportamento), Schumpeter na economia -, porem seus autores elaboram os trabalhos enfocando cada dessas vertentes de forma isolada.

Na teoria do desenvolvimento econômico teorizado por Schumpeter, pode-se observar que ele dedica especial atenção aos efeitos dos produtos e processos inovadores no desenvolvimento econômico. Também segundo Schumpeter a destruição criativa retrata a verdadeira face do dinamismo e evolucionário capitalismo. As transformações econômicas são induzidas Poe essas novas combinações que atuam no fenômeno da destruição criativa como um processo de transformação radical e reformulação do antigo. A sistemática da destruição criativa altera a estrutura existente e promove a criação de novas indústrias, as quais ultrapassam as existentes.

Segue abaixo a representação gráfica do modelo de Schumpeter referente à destruição criativa:

\begin{tabular}{|c|c|c|c|c|c|}
\hline $\begin{array}{l}\text { Eventos } \\
\text { exógenos } \\
\text { ciência e } \\
\text { invenção }\end{array}$ & $\begin{array}{l}\text { Atividades } \\
\text { empreendedoras }\end{array}$ & $\begin{array}{l}\text { Investimentos } \\
\text { em novas } \\
\text { tecnologias }\end{array}$ & $\rightarrow \begin{array}{l}\text { Novos } \\
\text { modelos } \\
\text { de } \\
\text { produção }\end{array}$ & $\begin{array}{l}\text { Mudanças } \\
\text { nas } \\
\text { estruturas } \\
\text { dos } \\
\text { mercados }\end{array}$ & $\begin{array}{l}\text { Lucros ou } \\
\text { perdas } \\
\text { oriundas } \\
\text { da } \\
\text { inovação }\end{array}$ \\
\hline
\end{tabular}

Figura 1: Destrição Criativa de Shumpeter baseado no trabalho de FREEMAN (1998)

Segue abaixo um quadro apresentando uma serie de definições elaboradas a partir das visões dos autores, para os termos de empreendedor e empreendedorismo: 
Quadro 1 - Definição para empreendedor e empreendedorismo

\begin{tabular}{|c|c|}
\hline Autor & Definição \\
\hline Richard Cantillon (1730) & $\begin{array}{l}\text { Empreendedor é definido como uma pessoa com atividade autônoma; } \\
\text { empreendedores promoveriam suas atividades para atender as } \\
\text { demandas do mercado. }\end{array}$ \\
\hline Jean-Baptiste Say (1810) & $\begin{array}{l}\text { Muitos talentos gerenciais são requeridos, necessários, para ser um } \\
\text { empreendedor de sucesso; muitos obstáculos e incertezas } \\
\text { acompanham o empreendedorismo. }\end{array}$ \\
\hline Alfred Marshall (1890) & $\begin{array}{l}\text { As habilidades para ser um empreendedor são diferentes, ainda que } \\
\text { complementares às exigências para ser um gestor }\end{array}$ \\
\hline Joseph Schumpeter (1910) & $\begin{array}{l}\text { Empreendedorismo é, na sua essência, a descoberta e a promoção de } \\
\text { novas combinações de fatores de produção; é a fonte principal de } \\
\text { criação do fator socioeconômico. }\end{array}$ \\
\hline Frank Knight (1920) & $\begin{array}{l}\text { A coragem para enfrentar a incerteza é o aspecto essencial do } \\
\text { empreendedorismo; empreendedores são requeridos para executar } \\
\text { cada função gerencial fundamental, como responsabilidade de dirigir e } \\
\text { controlar. }\end{array}$ \\
\hline Edith Peneroso (1960) & $\begin{array}{l}\text { Capacidade de gerenciar pode ser diferenciada da empreendedora; } \\
\text { identificar e explorar ideias para expansão das micro e pequenas } \\
\text { empresas é o aspecto essencial do empreendedorismo. }\end{array}$ \\
\hline Israel Kirzner (1975) & $\begin{array}{l}\text { A identificação de oportunidades de mercado é a função fundamental } \\
\text { do empreendedor. }\end{array}$ \\
\hline Harry Leibenstein (1980) & $\begin{array}{l}\text { Atividade empreendedora é indicada para redução de ineficiência } \\
\text { organizacional, com o intuito de reverter a entropia organizacional. }\end{array}$ \\
\hline
\end{tabular}

Fonte: Elaboração própria

O século XX pode ser reconhecido como a era dos computadores, o século XXI nascerá na biotecnologia, o homem passa de espectadores passivos da natureza para cativos coreógrafos.

\subsection{O DESENVOLVIMENTO LOCAL SUSTENTÁVEL E O PNEU ECOLÓGICO}

Prioritariamente, será abordado separadamente o conceito de desenvolvimento local, para compreender melhor como pode ocorrer o desenvolvimento local sustentável. Apenas em meados do século XX começou-se a ser estudado no Brasil a cerca do desenvolvimento local, em busca de identificar estratégias que contribuíam para a valorização local, economicamente falando. Para Dowbor e Martins (2000, p.17) "quanto mais à economia se globaliza, mais a sociedade tem também espaços e necessidades para criar âncoras locais". As primeiras civilizações deixaram de ser nômades quando criaram suas próprias âncoras, as quais simbolizam algo que faz com que as pessoas tenham motivos de permanecer em determinado local, por um médio ou longo espaço de tempo. Assim, criaram famílias, fixaram moradias e estabeleceram suas próprias formas de trabalho e sustento.

Com o passar dos tempos no Brasil, por exemplo, homens com maior poder aquisitivo criaram suas empresas passando a explorar econômico e socialmente seus estados, suas cidades, sua localidade.

Segundo De Paula (2008) o desenvolvimento local é:

"o processo de aproveitamento das vantagens comparativas e competitivas de uma localidade, para favorecer seu crescimento econômico, melhorar a qualidade de vida da sua população, fortalecer o seu capital social promover uma boa governança e o uso sustentável dos seus recursos naturais" (DE PAULA, 2008 apud KRONEMBERGER, 2001, p. 31). 
Para tanto Alcoforado (2006, p. 86) define desenvolvimento local nesta nova perspectiva como:

\begin{abstract}
"uma nova estratégia de desenvolvimento, em que a comunidade assume um novo papel: de comunidade demandante, ela emerge como agente, protagonista, empreendedora, com autonomia e independência". Essa estratégia tem como principal objetivo a melhoria da qualidade de vida de associados, familiares e da comunidade, maior participação nas estruturas do poder, ação política com autonomia e independência, contribuindo assim para o real exercício da democracia e para a utilização racional do meio ambiente, visando o bem-estar da geração presente e futura.
\end{abstract}

Visar o bem-estar das gerações futuras é preocupar-se com o desenvolvimento de hoje. Neste trabalho cita-se a importância da utilização do pneu ecológico para a sociedade e como é válida a participação da comunidade neste processo. No inicio dos tempos era muito difícil um cidadão ter um carro, bicicleta ou moto, devido à condição econômica em que as pessoas viviam. Atualmente tais meios de locomoção estão mais acessíveis, de maneira que houve um aumento sobressalente da quantidade de pneus que são descartados. Vale ressaltar que as empresas fabricantes de pneus também são responsáveis pelo descarte de pneu, pois quando um pneu é fabricado com defeito, ou seja, inservível para a sociedade, eles tem que ser descartado de forma correta.

Uns dos problemas mais perceptíveis nos últimos anos foram causados pela industrialização, pois a destinação dos resíduos nem sempre é feita de forma correta. Os resíduos sólidos, líquidos ou gasosos que sobram do processo produtivo dos pneus são prejudiciais ao ambiente natural e, consequentemente, a saúde humana. Ao transitar pelas Br's, estradas e vias, veem-se pneus que foram descartados erroneamente. O pneu não é tóxico, mas leva uns 50 anos para se decompor na natureza, já que não é biodegradável. Além disto, quando exposto de maneira irregular, ele acaba por se transformar em lugares ideais para a proliferação dos mosquitos, causadores de doenças como a dengue e a malária.

Segundo Quazi et al. (2001), o desenvolvimento sustentável visa um equilíbrio entre crescimento econômico e proteção ambiental. É muito lenta a conscientização sobre os cuidados que deveriam ser tomados em relação à capacidade de sustentação ambiental, embora, verificase um esforço mundial em relação à preservação do ambiente e da importância da busca das gerações pelos modos de desenvolvimento autossustentáveis.

O conceito de desenvolvimento local sustentável foi abordado no relatório produzido pela Comissão Mundial para o Meio Ambiente e Desenvolvimento - CMMAD (1991, p. 49), Comissão Brundtland - Relatório Nosso Futuro Comum ou Relatório de Brundtland. É um processo de transformação no qual a exploração dos recursos, a direção dos investimentos, a orientação do desenvolvimento tecnológico e a mudança institucional se harmonizam e reforçam o potencial presente e futuro, a fim de atender às necessidades e as aspirações humanas. Existem várias definições de desenvolvimento local sustentável, no entanto, diga-se que apenas 01 (um) conceito é o mais conhecido, pois é o que mais se aproxima do sucesso, caso seja colocado em prática. Este conceito foi citado no Relatório de Brundtland. Este relatório diz que desenvolvimento sustentável é "aquele que atende às necessidades do presente sem comprometer a possibilidade de as gerações futuras atenderem às suas próprias necessidades" (CNUMAD, 1991, p. 46) 
As empresas fabricantes de pneu, sempre atenderam a sociedade através do carro, moto, bicicleta, avião, etc., porém, após vários anos de fabricação e descarte incorreto do pneu inservível, as gerações do presente e futuro têm vivido em um meio ambiente que tem sofrido grande impacto negativo, devido à falta de consciência ambiental.

A Associação Brasileira de Empresas de Tratamento, Recuperação e Disposição de Resíduos Especiais relata que anualmente no Brasil são gerados cerca de 2,9 milhões de toneladas de resíduos sólidos e desses, apenas 600 mil toneladas, ou seja, 22\% recebem tratamento adequado. Dos rejeitos industriais tratados, $16 \%$ vão para aterros, $1 \%$ é incinerado e os $5 \%$ restantes são coprocessados, ou seja, transformam-se, por meio de queima, em parte de matéria-prima para a fabricação de cimento (ABETRE, 2007).

Segundo ANDRIETTA (2002) diversas outras formas de aproveitamento ou reciclagem podem ainda ser destacadas:

- recauchutagem ou reforma: o pneu não deve apresentar cortes, deformações e a banda de rodagem em condições que permitam sua aderência ao solo, para que se possa realizar a reforma.

- recuperação: trituração dos pneus e moagem dos resíduos, reduzidos a um pó fino. Os pneus recuperados são utilizados na mistura com asfalto para pavimentação e nas fábricas de cimento.

- regeneração ou desvulcanização: a borracha é separada dos demais componentes e desvulcanizada, passando por modificações que a torna mais plástica e apta a receber nova vulcanização, sem as mesmas propriedades da borracha crua.

A partir desta breve explanação sobre o desenvolvimento local sustentável relacionado ao segmento de pneu, tem-se a necessidade de trazer a este trabalho as relações ecológicas existentes no meio ambiente, as quais estão diretamente ligadas ao ciclo de vida do pneu, pelo qual segue o aporte teórico necessário.

\subsection{O ASPECTO AMBIENTAL E OS IMPACTOS NAS RELAÇÕES ECOLÓGICAS}

A avaliação do impacto do pneu no planeta, no aspecto da sustentabilidade há que avaliar o seu ciclo de vida. Esta avaliação é muito subjetiva, depende de muitos fatores e os seus procedimentos estão normalizados pela série de normas ISO 14040.

O trabalho publicado pelo site "BLIC"1 conduziu em 2001 um extenso estudo de análise de ciclo de vida dos pneus e concluiu que a fase do ciclo de vida com maior efeito negativo no ambiente é a fase de utilização, como podemos perceber na Figura 2.

Esta responsabilidade é atribuída considerando a quantidade de energia que movimenta o veículo com o objetivo de vencer a força em oposição do pneu ao movimento. Desta oposição resulta não só o consumo de combustível, como a degradação do próprio pneu, cujos restos se acumulam na natureza. De acordo com estes resultados, não restam dúvidas que o parâmetro em que deve haver maior esforço de melhoria é o da resistência ao rolamento do pneu

${ }^{1}$ Página da ETRMA, http://www.blic.be, Bruxelas, 2001, consultada em 10-12-2012 
Segundo Kromer, S.et al, 2006, em trabalho publicado, veio confirmar que a fase de maior impacto global é a fase de utilização. Mais se esclarece, neste estudo da Continental AG, que a fase de utilização não representa o maior impacto nas classes "consumo de água", "impactos negativos nas águas residuais" e "resíduos". Para estas classes a fase com maior impacto é a fase de "Aquisição de Matérias-primas". Neste estudo a produção é separada em Aquisição de Matériasprimas e Produção, propriamente dita.

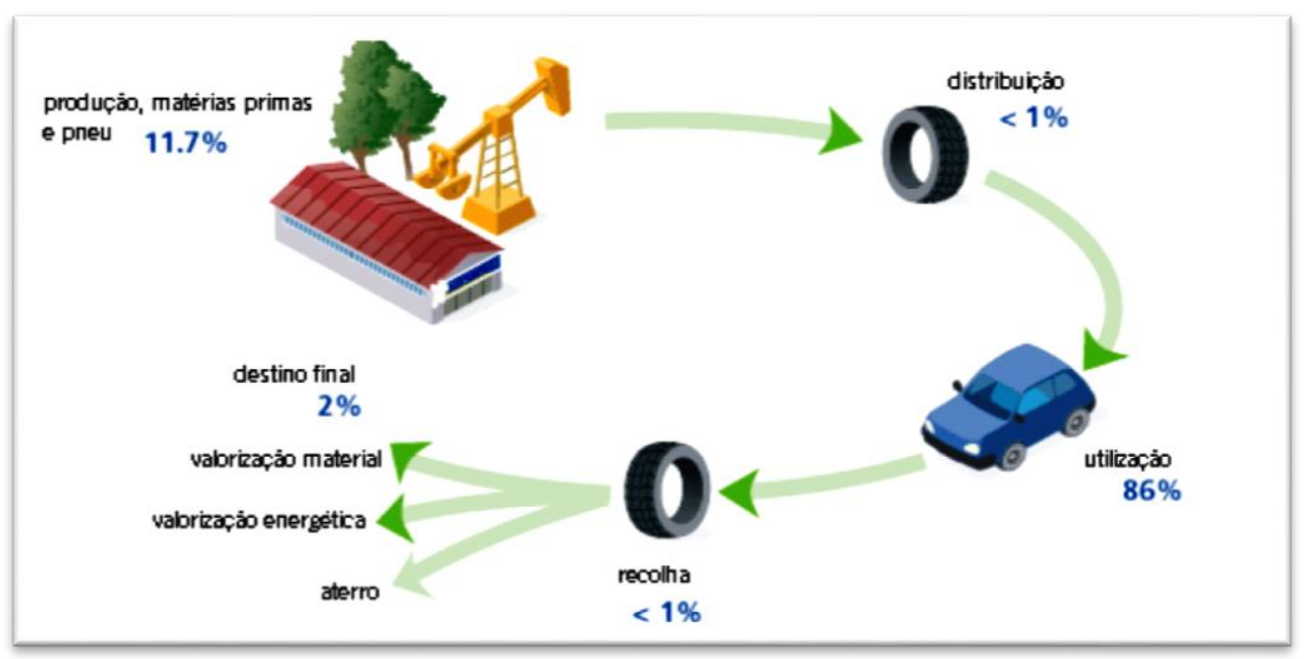

Figura 2 - Ciclo de vida dos Pneus e seu percentual de impacto ambiental Fonte: BLIC (2001)

Em qualquer dos estudos o impacto negativo da reciclagem e valorização, incluindo a recolha, é muito reduzido, sendo inferior aos 3\%, no global. O estudo da Continental é feito considerando só o mercado alemão e excluindo da análise os impactos da reciclagem material, dedicando atenção só à recauchutagem e valorização energética na produção de cimento e na produção de energia.

Nos países desenvolvidos, segundos dados internacionais são usados, aproximadamente, o equivalente a um pneu de automóvel ligeiro por habitante por ano, ou seja $9 \mathrm{~kg} / \mathrm{habitante} / \mathrm{ano}$, (Sistema de Gestão Ambientalmente Sustentável de Pneus - SGASP, 2005)Não havendo interesse comercial na reciclagem de pneus usados, estes passaram a ser amontoados em enormes depósitos. Alguns depósitos atingiram milhões de pneus em pilhas, ao ar livre.

Estes depósitos trazem graves problemas no aspecto ambiental e também de saúde pública. Quando expostos ao ar livre, conforme Figura 3, armazenam água das chuvas no seu interior, essa água acumulada e parada são óptimas para a procriação e multiplicação de mosquitos promovendo um desequilíbrio nas relações ecológicas do ecossistema envolvido. Outro problema está, em caso de incineração das pilhas, está queima além da poluição atmosférica traz graves consequências ambientais.

A formação das poças de água tem especial relevância nos países tropicais onde os mosquitos são importantes vectores de propagação de doenças como a malária, o dengue e a febre-amarela. (Sistema de Gestão Ambientalmente Sustentável de Pneus - SGASP, 2005).

A queima de pneus ao ar livre deve ser evitada pois dada a complexa composição química, essencialmente compostos de carbono orgânico com enxofre e com presença de cloro ou bromo, 
a combustão não controlada a baixas temperaturas leva à formação de compostos extremamente tóxicos como, por exemplo, as dioxinas. Acresce ainda a elevadíssima quantidade de matéria particulada, ver Figura 4, que se liberta dado à combustão ser incompleta.

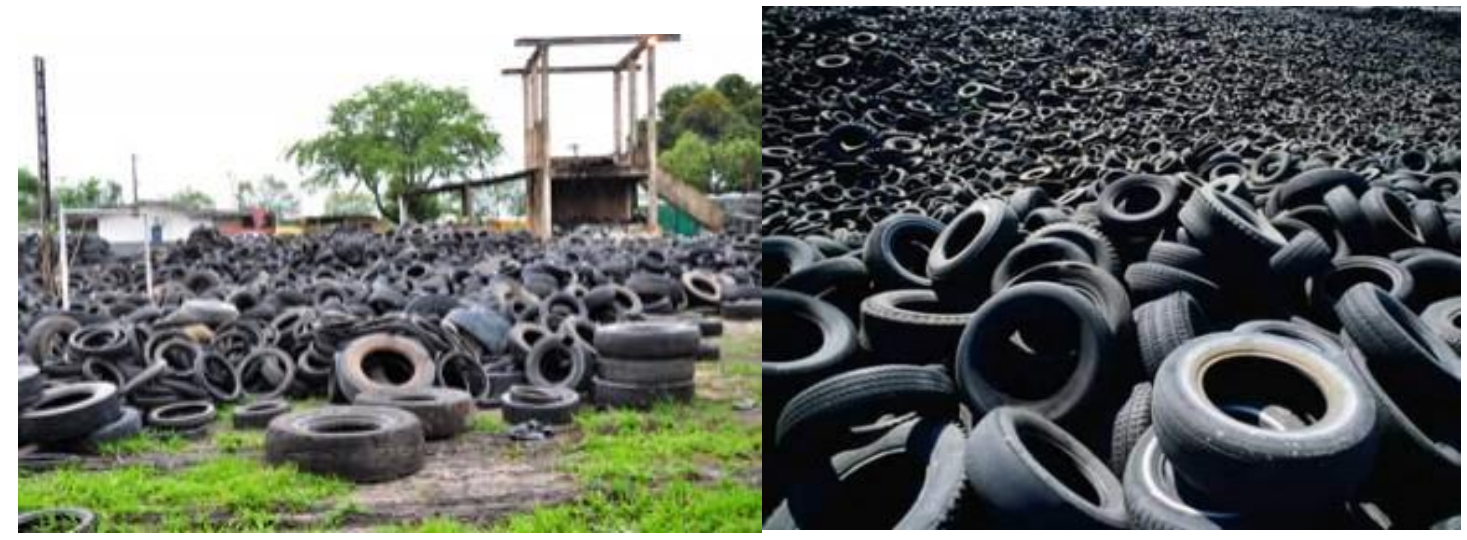

Figura 3 - Acumulação de Pneus na Cidade de Manaus - AM Fonte: FolhaBV, 2012

Na combustão dos pneus há libertação de óleos, que, espalhados no solo e aquíferos, têm grande potencial poluente. (Sistema de Gestão Ambientalmente Sustentável de Pneus - SGASP, 2005). Por estes motivos, quer a queima a céu aberto quer a deposição ao ar livre, têm estado a ser proibidas por todo o mundo.

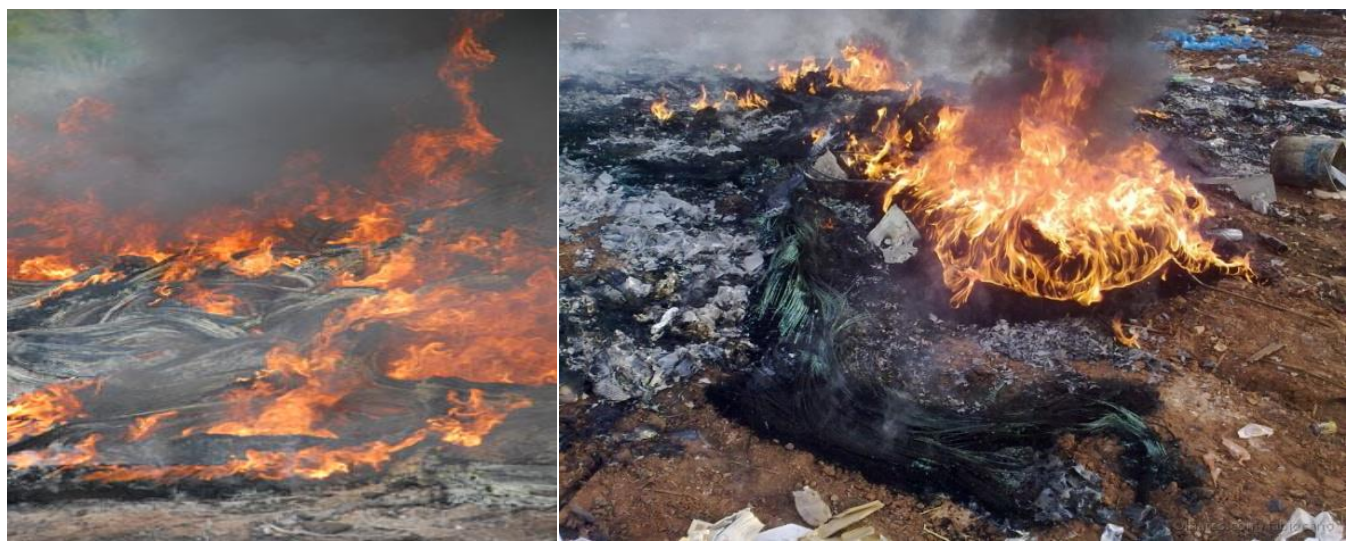

Figura 4 - Queima de Pneus em Aterros sanitários na cidade de São Paulo Fonte: Folha da Região, 2012

A eliminação de pneus por deposição em aterros sanitários também não é aconselhável porque, dada a sua forma, ocupa muito espaço e cria problemas de estabilidade nos aterros que não podem ser compactados convenientemente. Os espaços vazios deixados nos aterros são excelentes para a propagação de roedores.

O Brasil foi um dos países pioneiros na implementação de regulamentação para o problema da destinação dos pneus. As interações entre organismos vêm merecendo cada vez mais a atenção de pesquisadores. É fato que a maioria das espécies hoje viventes, necessariamente se engaja em pelo menos uma interação interespecífica ao longo de seu ciclo de vida (BRONSTEIN, 1994).

Neste sentido O CONAMA, Conselho Nacional do Meio Ambiente (do Brasil), veio em 1999 e de forma revolucionária à data, implementar a resolução 258/99, Agosto de 1999, que não possuía paralelo noutros países. Nesta resolução são fixados limites mínimos para a recolha e 
disposição adequada de pneus usados e atribuída ao produtor/importador a responsabilidade pela sua execução.

Os procedimentos de implementação desta Resolução do CONAMA foram instituídos pela Instrução Normativa no08/02 do IBAMA, Instituto Brasileiro do Meio Ambiente e dos Recursos Naturais Renováveis. (Cimino, M,A; Zanta V,M, 2005)

Estava prevista a Revisão em 2005, pelo que foi apresentado à Presidência da República, em Junho de 2005, o Projeto de Lei no 6136/2005 afim de instituir o Sistema de Gestão Ambientalmente Sustentável de Pneus - SGASP.

Neste diploma pretendia-se também elevar à categoria de obrigação legal a responsabilidade dos produtores pelo destino final dos resíduos dos pneus, e sua trituração, definir claramente os conceitos de pneu novo e pneu usado e, por último, proibir determinantemente a importação de pneus usados ainda que reformados, recauchutados ou rechapados. (Cimino, M,A; Zanta V,M, 2005)

O pneu é um produto quimicamente muito estável e a sua capacidade calorífica é muito elevada, sendo mesmo superior à de muitos carvões.

Assim sendo e havendo a obrigatoriedade de triturar os pneus, também não faz sentido fazer a sua deposição em aterro: uma vez que triturados podem, e devem, ter aproveitamentos que rentabilizem a operação de trituração e permitam diminuir a exploração e extração de matérias-primas.

Os pneus na ótica das relações ecológicas são um problema enquanto resíduo e também um problema enquanto consumo de recursos naturais, em especial de petróleo mas também, entre outros, de ferro, enxofre e zinco, a falta de um processo de reaproveitamento deste material acarreta sérios danos aos ecossistemas.

\subsection{CARACTERIZAÇÃO DA EMPRESA ESTUDADA}

O estudo de caso é a empresa Pneu Verde Recicladora e Comércio de Resíduos Ltda, com sede à Rua Lourenço de Sá, 165, no bairro de São José, no município do Recife, em Pernambuco. Foi constituída em 05 de maio de 2011 porém, já havia uma OCIPE - DSHT, realizando pesquisa desde 2008, sobre a viabilidade de retirar o resíduo pneu inservível do meio ambiente.

A Pneu Verde é composta por dois sócios, um coordenador, um comercial, um líder de manutenção e cinco auxiliares de linha de produção. Como destinadora final do resíduo sólido pneus, obteve o reconhecimento, no ano de 2012, entre as 15 empresas brasileiras que mais destinaram pneus inservíveis. Há no Brasil cerca de 400 pontos de coleta de pneus inservíveis espalhados pelos distritos federativos, conforme a tabela 1 abaixo:

Tabela 1 - Distribuição da coleta de pneus inservíveis nos distritos federativos

\begin{tabular}{|l|c|l|c|}
\hline \multicolumn{1}{|c|}{ ESTADOS } & PONTOS DE COLETA & ESTADOS & PONTOS DE COLETA \\
\hline RS & 44 & SC & 08 \\
\hline PR & 46 & SP & 112 \\
\hline MS & 12 & RJ & 18 \\
\hline ES & 09 & MG & 92 \\
\hline BA & 10 & GO & 13 \\
\hline
\end{tabular}




\begin{tabular}{|l|c|l|l|}
\hline SE & 02 & AL & 01 \\
\hline PE & $05^{*}$ & PB & 03 \\
\hline RN & 03 & CE & 05 \\
\hline PI & 01 & TO & 05 \\
\hline MA & 03 & PA & 05 \\
\hline MT & 12 & RR & 01 \\
\hline
\end{tabular}

A importância da coleta de pneus levou os fabricantes de pneus novos a criar a Reciclanip, entidade sem fins lucrativos, que tem como empreendedores a Bridgestone, Continental, Goodyear, Michelin e Pirelli. Sendo o seu foco na coleta e destinação de pneus inservíveis no Brasil. Com a Resolução do CONAMA $n^{\circ} 416 / 2009$, que determina os fabricantes e os importadores com a obrigação de coletar e dar destinação final ambientalmente adequadas ao pneu inservível.

A Pneu Verde além de contribuir com a destinação final gera o ciclo de renovação, no momento em que, no primeiro ano de atuação recolheu 1800 toneladas de pneus destinados e na semana de 17 a 20/12/2012, havia destinado 3400 toneladas. Isso ocorre através de parcerias com órgãos públicos e empresas privadas, podemos observar na figura 5 o acumulo dos pneus na Empresa.

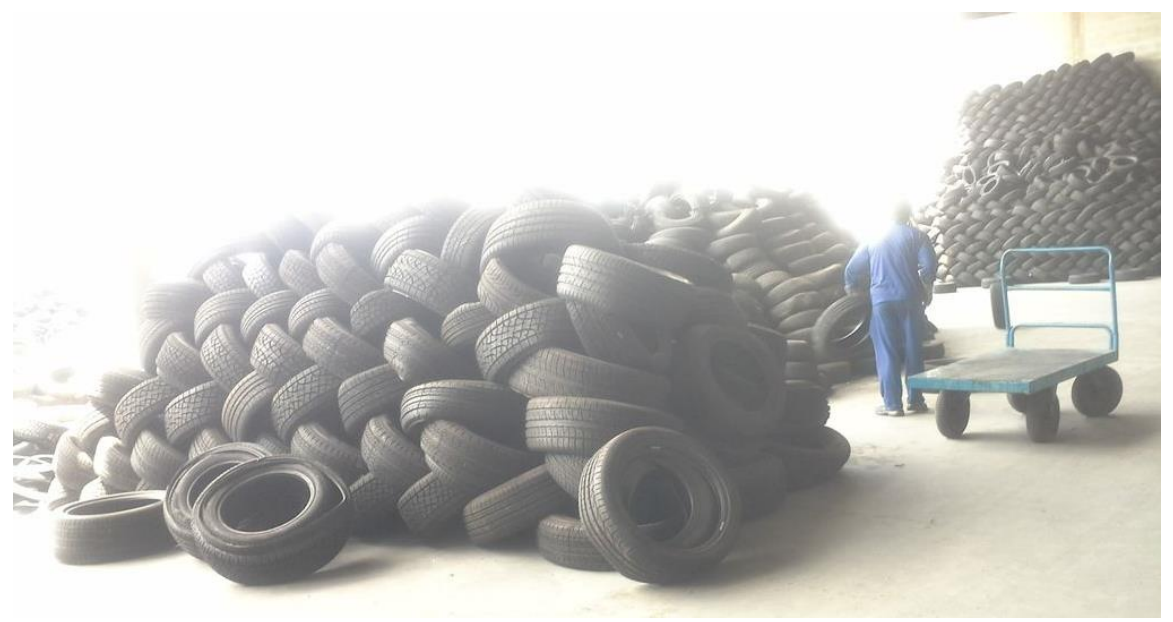

Figura 5 - Acumulação de Pneus na Empresa Pneu Verde

Atualmente a Prefeitura da Cidade do Recife é a maior parceira, as locadoras, empresas de ônibus, consórcio de aterro sanitário, além da Pirelli, fabricante de pneus, que envia os pneus reprovados. Com a implantação do "Disque Coleta", a Pneu Verde espera atingir a todo o segmento da sociedade e as empresas que desejam destinar seus pneus inservíveis, sem qualquer custo. Para isso, é estabelecido um roteiro prévio para coleta. Além de receber em seu endereço os pneus. que vem através do cidadão comum e até das cidades como: Fortaleza e Salvador, chegando a receber uma carreta a cada quinze dias e de 3 a 4 toneladas de pneus inservíveis por dia. Apesar de trabalhar apenas com pneus com até $1,20 \mathrm{~m}$ de altura (carro passeio, moto e bicicleta) mais como é gerenciadora, ela destina a Cimenteira aqueles pneus que ultrapassam este limite. A Cimenteira é licenciada pelo IBAMA e tem níveis aceitáveis de poluentes, conforme a legislação. E com empresas interessadas em fazer a destinação de pneus inservíveis, a Pneu Verde firma um termo de parceria.

O processo da Pneu Verde inicia com o corte em bandas de 1 tonelada de pneus que são colocados em cada auto clave, havendo 6 auto claves, que totaliza 6 toneladas de pneus processados por dia, de tecnologia Ucraniana e Italiana, além do equipamento para aferir a 
temperatura e pressão de tecnologia Russa. Foram realizadas algumas modificações neste equipamento para atender as normas e a legislação brasileira que são extremamente rigorosas. Atua por meio do processo de Pirolise, que consiste no aquecimento dos fragmentos de pneus a temperaturas de $400 \circ \mathrm{C}$ em espaço confinado, sem oxigênio, por 7 horas. Podemos observar este processo na Figura 6. A esta temperatura, a borracha dos pneus começa a se decompor gerando uma variedade de produtos gasosos e líquidos, basicamente hidrocarbonetos. Estes produtos podem ser coletados, deixando um resíduo não volátil composto de carbon black, pedaços de arame de aço carbônico e vários materiais inorgânicos, tais como pigmentos de óxido de titânio, sílica, óleo residual também chamado de pneu líquido e gás. Com 3 horas e meia de aquecimento a segunda autoclave já é acionada por gerar gás o suficiente para iniciar o seu processo.

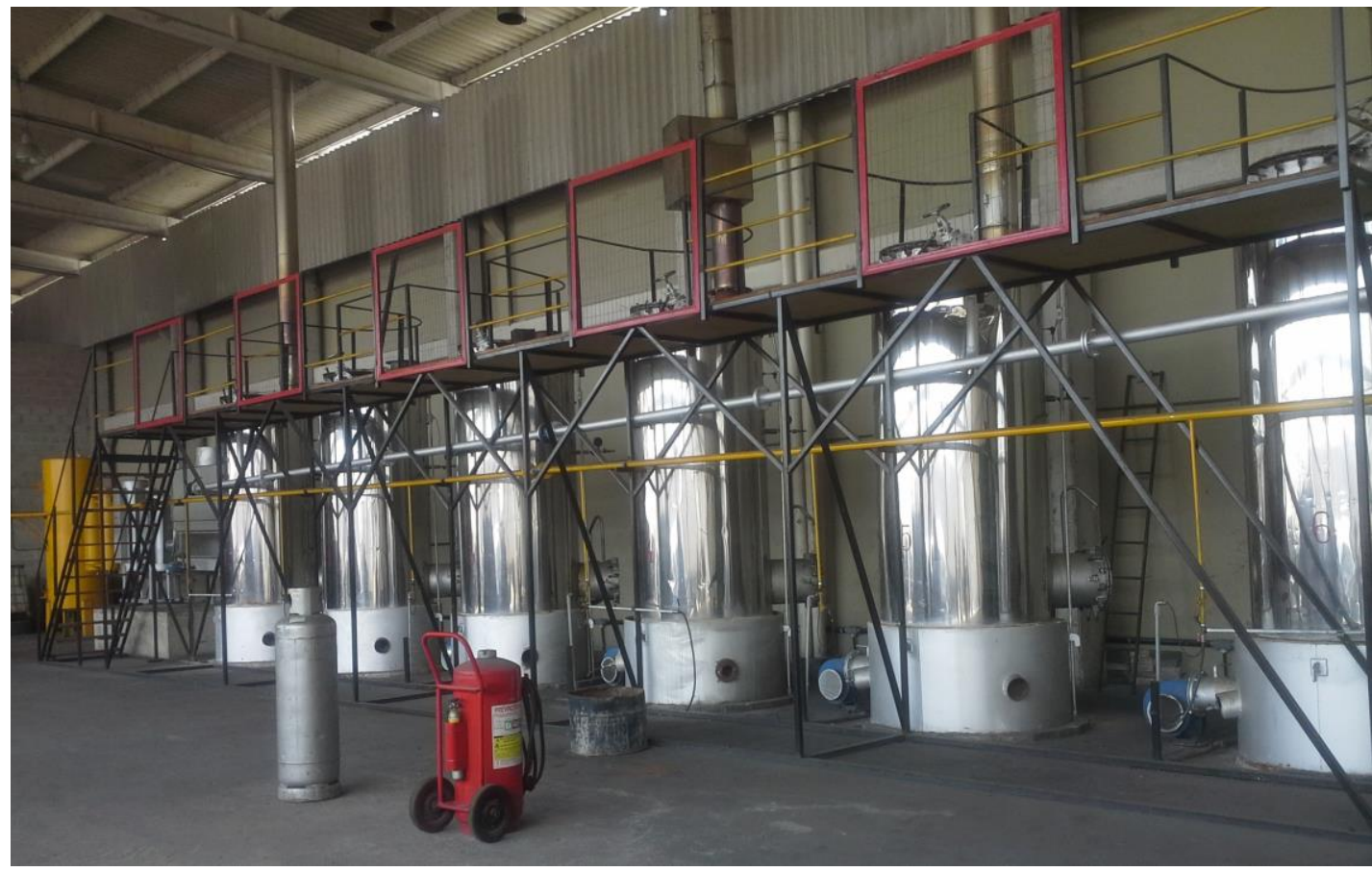

Figura 6 - Pirólise na empresa Pneu Verde

A Pneu Verde informou que ao realizar a análise comparativa preliminar com o processo realizado na Ucrânia, verificou que: o valor agregado poderia ser utilizado em outro segmento como por exemplo o carbon black, pode ser utilizado como carga reforçante e também pigmentação; que quanto menor a mica maior o poder de absorção servindo para fazer peças de borracha, banda de rodagem (está em teste) além de outras infinitas possibilidades; o fato de não gerar nem $1 \%$ de resíduo para ser jogado fora; quando a máquina é desligada pode vir a sair um pouco de borra e ela pode ser reiniciada até o resíduo de pneu ser totalmente processado; há a separação manual do carbon black do aço; o óleo residual inatura, fizeram testes e identificaram que podem conseguir uma tinta que serve para pintar pneus e ser utilizada em lavajatos; o óleo inatura pode ser utilizado em caldeiras, porém se passar por um processo de destilação o índice de alcano é de $79,6 \%$. Ao compararmos com a gasolina que é de $86 \%$ ver-se que a diferença é muito pequena, sendo também um tipo similar de combustível. Neste processo foi identificado um solvente e a pesquisa continuada vendo o mercado, está em andamento.

Em Minas Gerais, unidade federativa do Brasil, foram realizadas pesquisas de utilização como combustível ao ser colocada de forma fracionada e adicionada em um gerador pode permitir 
o seu funcionamento. Neste caso para um gerador com capacidade para 20 litros, $40 \%$ foram adicionados de combustível normal e 60\% foram de óleo residual do pneu.

O carbon black possui alta concentração de enxofre, o óleo tem alto poder calorífico e durante o processo começa a gerar o gás e há a extração deste óleo.

O resfriamento ocorre com 7 ou 8 horas para que se possa abrir a auto clave e extrair o carbon black e o aço.

Durante o processo há a geração de gás que pode ser utilizado como energia, há estudos, "in loco", com comparações técnicas em laboratórios conceituados no país. O gás gerado será requerido como combustível para o processo e o restante, em princípio, pode ser vendido. Similarmente, a fração líquida leve pode ser vendida como gasolina. O considerável volume de óleo resultante pode ser usado como massa de borracha por fabricantes de pneus. $\mathrm{O}$ aço pode ser coletado magneticamente e vendido como resíduo de aço e o resíduo carbonífero pode ser vendido como combustível.

Em termos de destinação, hoje como recicladora no país, só existe a Pneu Verde porque $80 \%$ dos pneus do nosso país é destinado as Cimenteiras. Em tecnologia a Pneu Verde é pioneira e necessita explorar a comercialização dos produtos extraídos do processo para as indústrias de borracha, situadas na região Sul e Sudoeste do Brasil, onde produz peças de borracha e o óleo em empresas que trabalham com caldeira. Como combustível está sendo analisado, pois é necessário obter uma licença da Petrobras para realizar a pesquisa.

\section{METODOLOGIA}

Para o desenvolvimento deste artigo científico, pensou-se em abordar uma questão que está presente na maioria da vida das pessoas e que, no entanto, ocorre um grande problema referente ao impacto ambiental: o descarte de pneus.

Com isto, buscou-se analisar como a empresa Pneu Verde reforma pneus inservíveis, tomando conhecimento de toda cadeia produtiva. Assim, esta pesquisa contemplou estudos empíricos e teóricos, a fim de contribuir para a socialização do impacto gerado no meio ambiente pelo resíduo sólido.

Para atingir os objetivos propostos, foi realizada uma pesquisa exploratória que, segundo Pacheco Júnior, Pereira, Pereira Filho (2007, p. 83) "exige uma maior profundidade na coleta de dados para geração de conhecimento, especialmente por ser necessário revelar os elementos de uma parte ou de todo um processo".

Faz parte da natureza deste trabalho a pesquisa bibliográfica, pois ela serve para fundamentar e direcionar os estudos em busca dos resultados, com base na literatura existente.

Sobre abordagem de pesquisa, utilizou-se a qualitativa que, segundo Oliveira, M., 2008, p.60) "buscar informações fidedignas para se explicar em profundidade o significado e as características de cada contexto em que se encontra o objeto de pesquisa. Os dados podem obtidos através de uma pesquisa bibliográfica, entrevistas, questionários [...]

Para tanto, foi feita uma visita a empresa Pneu Verde, com o objetivo de conhecer os processos que envolvem a destinação do pneu inservível, os quais serão detalhados 
posteriormente. Para melhor compreensão das atividades da Pneu Verde, empresa objeto de estudo do segmento de destinação de pneu, como técnica para coleta de dados, utilizou-se a técnica da entrevista aberta.

Por meio da entrevista foi possível identificar quais as relações ecológicas que o pneu mantém envolvendo o seu ciclo de vida, assim como o benefício causado à sociedade quando o pneu é descartado de forma correta.

\section{RESULTADOS E DISCUSSÕES}

A iniciativa do "Disque Coleta", implantada pela Pneu Verde, pode ser incrementada com o uso da mídia e pontos de coleta em locais públicos, de compra e de manutenção de veículos: concessionárias, borracharias, oficinas de veículos, locais de balanceamento de pneus, escolas, postos de combustíveis, shopping, mercados, ambientes públicos, associações de catadores, etc.

A Pneu verde precisa se cadastrar nas entidades constituídas pelos fabricantes para ter o seu endereço divulgado em sites que tratam deste assunto.

Pernambuco, unidade federativa do Brasil situada no Centro-leste da região Nordeste, divisa ao Norte com o estado do Ceará e o estado da Paraíba, ao Sul com os estados da Bahia e Alagoas, ao Oeste com o estado do Piauí e ao Leste com o Oceano Atlântico. Ocupa uma área de $98.937,8 \mathrm{Km}^{2}$. (Fonte: www.brasilrepublica.com/pernambuco.htm.), possui o Plano Estadual de Resíduos Sólidos de Pernambuco - PERS, elaborado em julho de 2012, devido a maturação de sua equipe técnica e dos trabalhos desenvolvidos ao longo dos anos pela antiga Secretaria de Ciência, Tecnologia e Meio Ambiente (SECTMA) e atual Secretaria de Meio Ambiente e Sustentabilidade (SEMAS), pela Secretaria das Cidades (SECID), pelo Programa de Apoio ao Desenvolvimento da Zona da Mata (PROMATA), pela Agência Estadual de Meio Ambiente (CPRH), pelo Instituto de Tecnologia de Pernambuco (ITEP) e pela Agência Estadual de Planejamento e Pesquisas de Pernambuco (CONDEPE/FIDEM).

Este Plano está pautado em um conjunto de diretrizes traduzidas na integração das políticas ambientais, com as demais políticas setoriais de governo, setor produtivo e sociedade civil, procurando agregar transparência e efetividade ao processo, conferindo-lhe legitimidade, além da implementação de ações do governo compartilhadas entre o poder público e os demais setores da sociedade. (PERS).

Para a construção do presente Plano foram considerados os documentos elaborados ao longo destes últimos anos: Diagnóstico de Resíduos Sólidos de Pernambuco/ 2006, III Conferência Estadual de Meio Ambiente/ 2008, As Políticas Públicas Ambientais do Estado de Pernambuco/2010, Lei Estadual 14.236/2010, que instituiu a Política Estadual de Resíduos Sólidos, Plano Metropolitano de Resíduos Sólidos/2011, Estudo de Regionalização da Gestão dos Resíduos Sólidos no Estado de Pernambuco e o Plano de Gestão Integrada de Resíduos Sólidos nos municípios inseridos na bacia hidrográfica do Rio São Francisco/2011, Mapa Estadual de Resíduos Sólidos/2011, Inventário Estadual de Resíduos Sólidos Industriais - Pernambuco /2003, Sistema Estadual de Informações sobre Resíduos Sólidos - RESOLPE /2009, Estudos dos Impactos dos Investimentos na Economia Pernambucana/2011, Pernambuco: Realidades e desafios/2009, além de publicações científicas, informações disponibilizadas por instituições públicas, privadas e sociedade civil, entre outros. 
O referido PERS foi construído com a participação da sociedade civil, por meio de reuniões técnicas e consultas públicas, refletindo um desejo coletivo dos pernambucanos e deixando de ser um trabalho apenas de governo. "(fonte: Plano de Resíduo Sólidos de Pernambuco).

Segundo a Resolução 416 do CONAMA, $\$ 1^{\circ}$, do Art. $8^{\circ}$, que trata sobre a implantação de pontos de coleta em pontos de comercialização, de pneus, os municípios, borracheiros e outros, num prazo de 01 (um) ano a partir da publicação desta Resolução, 30 de setembro de 2009, para os municípios acima de 100.000 (cem mil) habitantes, haja pelo menos um ponto de coleta.

Dessa forma podemos verificar que dos 186 (cento e oitenta e seis) municípios de Pernambuco, 12(doze) estão dentro desta obrigatoriedade e verificamos através das informações da consulta ao site: reciclanip.com.br/v3/pontos.coleta/brasil, em Pernambuco há 05 (cinco) pontos nos municípios do Cabo de Santo Agostinho, Garanhuns, Olinda, Paulista e São Lourenço da Mata. Apesar de não constar o município de Recife, este tem a Pneu Verde como ponto de coleta e destinadora final deste resíduo. E a Pneu Verde, como vimos tem estratégias para ampliar os pontos de coleta, implantou o "Disque Coleta" e estabelece parcerias com locadoras, borracharia, consórcios, empresas de ônibus, entre outros conforme detalhamos anteriormente.

Podemos observar abaixo na figura 7, o mapa de distribuição populacional do Estado de Pernambuco:

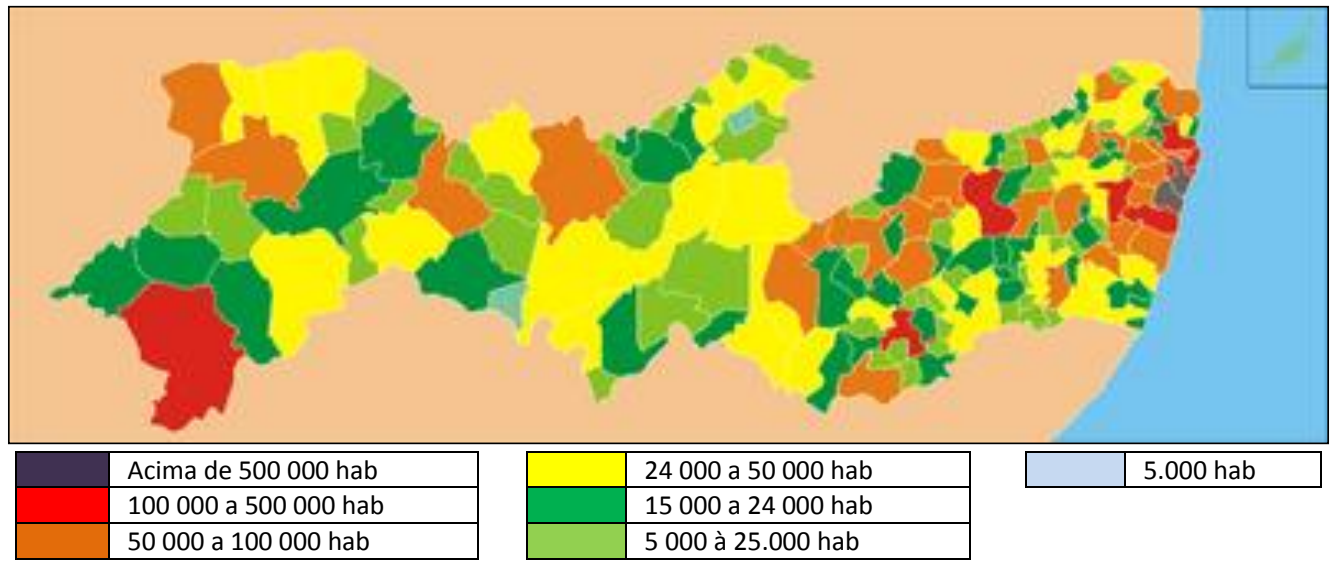

Figura 7 - Mapa de distribuição populacional do Estado de Pernambuco Fonte: IBGE,2011

E abaixo relacionamos os municípios de Pernambuco com população acima de 300.000 (cem mil) habitantes, segundo estimativas de 2011 do IBGE.

\begin{tabular}{|c|c|c|c|c|c|c|}
\hline Posição & 1 & 2 & 3 & 4 & 5 & 6 \\
\hline Município & Recife (RMR) & $\begin{array}{c}\text { Jaboatão dos } \\
\text { Guararapes (RMR) }\end{array}$ & $\begin{array}{c}\text { Olinda } \\
\text { (RMR) }\end{array}$ & Caruaru & $\begin{array}{c}\text { Paulista } \\
\text { (RMR) }\end{array}$ & Petrolina \\
\hline População & 1.546 .516 & 649.787 & 378.537 & 319.579 & 303.400 & 299.751 \\
\hline
\end{tabular}

Fonte: IBGE, 2011

\section{CONCLUSÃO}

Pode-se concluir dizendo que a pirólise pode converter grandes quantidades de pneus descartados em subprodutos úteis; porém, para ser rentável deve ser altamente subsidiada e/ou ampliada o número de auto claves, que tem seu fator limitante estabelecida atualmente em seis, pela Pneu Verde. 
Sabemos que muito ainda há de ser feito mais os fabricantes, desde 1999 até maio de 2012, já coletaram e destinaram mais de 2 milhões de toneladas de pneus inservíveis e fizeram um investimento em torno de U\$ 175 milhões, valor até maio de 2012, para coleta e destinação de pneus inservíveis. (RECICLANIP 2012). Mais temos a convicção que este resíduo ainda não faz parte da preocupação da sociedade organizada ou individual. A própria legislação não contempla o cidadão e isso deixa o tema confinado ao fabricante e distribuidor. Analisando isso vemos o valor da Pneu Verde em buscar parcerias e a disposição em investir em pontos de coleta; além do já implantado "Disque Coleta" e o direcionamento para as indústrias interessadas em obter os produtos resultantes da pirólise, vai alavancar a prática dos 3R: reciclar, reduzir e reutilizar e da logística reversa.

A esfera pública, por força da lei vem tentando disciplinar nas suas unidades federativas, por meio do Plano Estadual de Resíduos Sólidos, montando um sistema capaz de extrair do meio ambiente o que mais o danifica. Em Pernambuco o PERS, tem sua sistemática assim estruturada, conforme figura 8 abaixo:

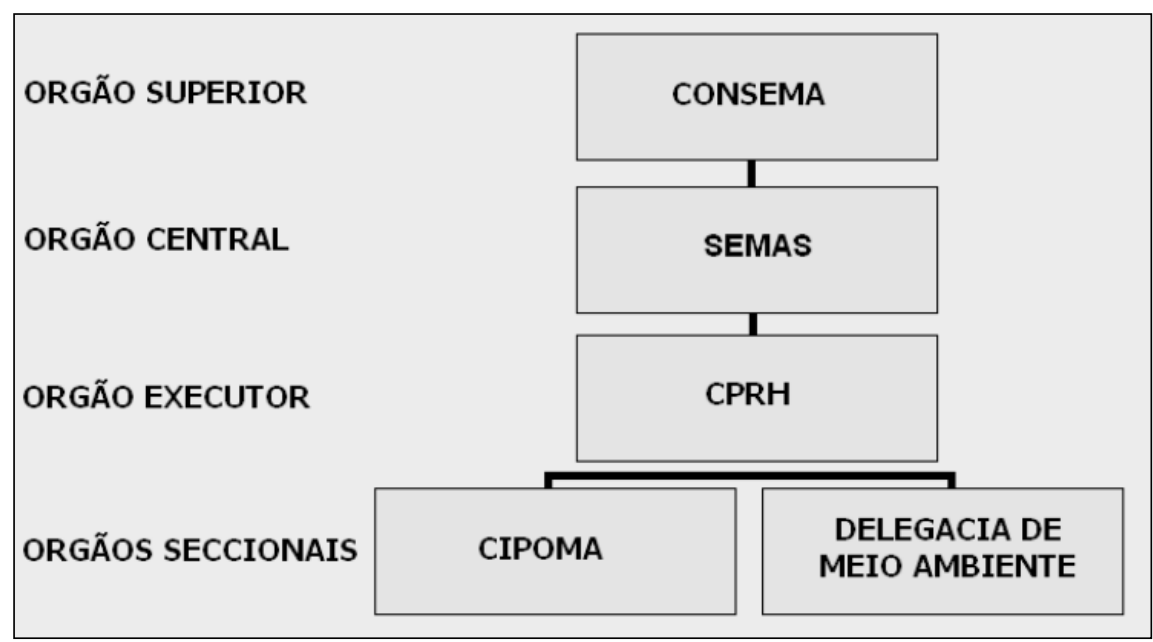

Figura 8 - Sistema de Resíduos Sólidos do Estado de Pernambuco

Fonte: Semas, 2012

Nesta figura podemos identificar que o Estado de Pernambuco é o responsável pela implementação da Política Estadual de Resíduos Sólidos, sendo constituído pelos órgãos e entidades acima apresentadas; assim como os fabricantes e distribuidores são por meio da Resolução 416 do CONAMA. Porém vemos que mesmo existindo a Lei e a Política, falta o controle e fiscalização do gerenciamento dos pneus descartados para fins de educação e disciplinamento do resíduo que é indeterminado o seu tempo de degradação no meio ambiente (Fonte: Secretaria do Meio Ambiente do Estado de São Paulo).

Outra perspectiva em relação a este resíduo sólido está no aproveitamento e aceitação como logística reserva na indústria siderúrgica, indústria de produtos confeccionados com borracha, indústria automobilística, indústrias que usem caldeiras, indústria moveleira, entre outras.

As relações ecológicas são estabelecidas entre seres vivos, pode ser dito que elas poderiam ser classificadas como Relações Interespecíficas, Harmônicas, inquilinismo por ser resíduo pneu um produto que ao se expor ao meio ambiente, serve de espaço para propício a endemias como por exemplo para o mosquito aedes aegypt, doenças parasitárias que podem contribuir para o 
aumento de doenças para o ser humano. Há preocupação também com a saúde das pessoas que adotam o hábito de descartar o pneu por meio de sua queima a céu aberto, liberando gases tóxicos na atmosfera, CO2 e Enxofre. E essas pessoas podem desenvolver doenças respiratórias, queimadura do aparelho respiratório e chegar até a morte. Neste caso não há relações ecológicas previstas mais uma prática criminosa ao meio ambiente e a vida humana. Sendo assim, a ação da Pneu verde traz um alento para a melhoria da qualidade do meio ambiente e da qualidade de vida dos seres vivos.

\section{REFERÊNCIAS BIBLIOGRÁFICAS}

1. ABETRE Associação Brasileira de Empresas de Tratamento, Recuperação e Disposição de Resíduos Especiais. Disponível em:http://www.ambientebrasil.com.br/composer.php3? base=./residuos/index.php3\&conte do=./residuos/lixo.html. Acesso: 18 fev. 2012.

2. Acúmulo de Pneus em aterros em Manaus. Disponível em: http://www.folhabv.com. br/noticia. php?id=130701. Acessado em: 20 de Dezembro de 2012.

3. ANDRIETTA, A. J. Pneus e meio ambiente: um grande problema requer uma grande solução. Out. 2002. Disponível em: http://www.reciclarepreciso.hpg.ig.com.br/recipneus. htm. Acesso: 18 fev. 2012.

4. BRONSTEIN, J.L., 1994. Our current understanding of mutualism. The Quarterly Review of Biology, 69: 31-51.

5. CIMINO M.A., ZANTA V.M., Gerenciamento de Pneumáticos Inservíveis (GPI): Análise Critica de Ações Institucionais e Tecnologias Para Minimização, Engenharia Sanitária Ambiental, Rio de Janeiro, Brasil, vol. 10 - no. 4, Out-Dez 2005, pp. 299-306.

6. COMISSÃO MUNDIAL PARA O MEIO AMBIENTE E DESENVOLVIMENTO - CMMAD NosSO futuro comum. 2. ed. Rio de Janeiro: FGV, 1991.

7. DOWBOR, L.; MARTINS, L. A comunidade inteligente: visitando as experiências de gestão local. Instituto Polis, 2000. Disponível em: www.dowbor.org. Acesso em: 12 Jan 2013.

8. DRUCKER, PETER F. Innovation and entrepreneurship practice and principles. London: Pan Books, 1986.

9. LEITE, Emanuel, O fenômeno do empreendedorismo, Recife: Editora Saraiva, 2012.

10. INSTRUÇÃO NORMATIVA CPRH N004/2012.

11. INSTRUÇÃO NORMATIVA CPRH N005/2012 LICENCIAMENTO AMBIENTAL.

12. LAKATO, Eva Maria; MARCONI, Marina de Andrade. Metodologia do trabalho científico. 4. ed. São Paulo: Atlas, 1995.

13. LEI N¹2.305, DE 2 DE AGOSTO DE 2010, PRESIDÊNCIA DA REPÚBLICA, CASA CIVIL, SUBCHEFIA PARA ASSUNTOS JURÍDICOS.

14. LEI N¹2.432 DE 29 DE SETEMBRO DE 2003, DISTRIBUIÇÃO DE PARTE DO ICMS PRA DESTINAÇÃO FINAL DE RESÍDUOS SÓLIDOS.

15. O ciclo de vida do Pneu. Disponível em: http://www.blic.be, Bruxelas, 2006, Acessado em 10 de Dezembro de2012.

16. OLIVEIRA, Maria M. Como Fazer Pesquisa Qualitativa. 2ª Ed. Petrópolis - RJ: Vozes, 2008. 
17. PACHECO JÚNIOR, Waldemar; PEREIRA, Vera Lúcia D. V.; PEREIRA FILHO, Hyppólito do Valle, pesquisa científica sem tropeços: abordagem sistêmica. São Paulo: Atlas, 2007.

18. QUAZI, H. A. et al. Motivation for ISO 14000 certification: development of a predictive model. Omega, Vol.29, 2001, p. 525-542.

19. Queima de pneus no interior de São Paulo. Disponível em: http://www.folhadaregiao.com.br/Materia.php?id=85713: Acessado em: 20 de Dezembro de 2012.

20. RESOLUÇÃO ANP N³9, DE 24.12.2008 - DOU 26.12.2008 - AGÊNCIA NACIONAL DO PETRÓLIO, GÁS NATURAL E BIOCOMBUSTÍVEL.

21. RESOLUÇÃO N416, DE 30 DE SETEMBRO DE 2009, PUBLICADA NO DOU N 118, DE 01/10/2009, PÁGS 64-66.

22. SILVA,M. Projeto de Lei que Institui o Sistema de Gestão Ambientalmente Sustentável de Pneus - SGASP, EM Interministerial no37/MMA/MS/2005, Brasília, 10 de Junho de 2005.

23. SILKE Krömer; ECKHARD Kreipe, DIETHELM Reichenbach, RAINER Stark, Cycle Assessment, of a Car Tire, Continental AG, Hannover, Alemanha, 2006. 